\title{
BETTER SAFE THAN SORRY
}

\section{Magistrates' views on the Domestic Violence Act $^{1}$}

Lillian Artz

Gender, Health and Justice Research Centre

University of Cape Town

As part of an ongoing project to monitor the implementation of the Domestic Violence Act, this article focuses on the role of magistrates. The impression exists that magistrates have a tendency to judge domestic violence matters conservatively. But research shows that most take a 'better safe, than sorry' approach in granting particular conditions in protection orders. The general sentiment is that it makes more sense to have an allinclusive protection order than one that will be subject to variation at a later stage.

T Domestic Violence Act 116 of 1998 (DVA) was promulgated in an attempt to provide victims with an accessible legal tool to stop domestic abuse. Though far-reaching in its definition of what constitutes an act of 'domestic violence' and 'domestic relationships', implementation has been slowed by considerable teething problems. Notwithstanding its inconsistent application by the courts, the intention of the Act has been marred by the everyday constraints facing courts as well as the limitations of what the Act itself, and its agents, can reasonably provide victims of domestic violence.

The study on which this article is based ${ }^{2}$ finds that magistrates interpret and apply the DVA differently. This is not necessarily a problem given the unlimited range of abuses committed in domestic relationships and the remedies available under the Act. What is striking, however, is the difference of approaches by magistrates to the basic procedural aspects of implementing the Act and the extent to which this has measurable implications on the effectiveness of the protection orders granted.
Issues relating to evictions or removal of respondents, emergency monetary relief, contact orders with children, the role of alcohol and drugs, withdrawal of applications and charges, emotional and psychological abuse, breaches of protection orders and the adjudication of cases where existing High Court orders are in place, are areas of great debate and contention among magistrates. The discussion in this article will however be limited to the broader debates about implementation of the Act by magistrates.

\section{Overall opinions of the Act}

Magistrates were generally of the opinion that the Domestic Violence Act is a progressive and useful piece of legislation. The substantive law was evaluated as "very good" although minor revisions were suggested to include sectors such as health, welfare and correctional services in the Act in order to ensure that service provision in domestic violence cases does not solely rest with the police and the courts. Recognising that domestic violence is a major social issue, with potentially serious outcomes for victims and their families, the 
exclusion of these sectors was seen as a major shortcoming of the DVA.

Interestingly, the inclusion of positive legal duties on the police was considered necessary, and some magistrates even suggested that these should be extended to other sectors as well. It was argued that independent monitoring systems within the criminal justice system were not sufficient to ensure performance. It was noted that the performance of the police in domestic violence cases had improved dramatically since the inception of the DVA and that the fear of being charged with dereliction of duty was a great incentive to this end.

Procedurally, the DVA was seen as cumbersome. With cramped courts, heavy caseloads and the fact that magistrates don't focus primarily on domestic violence cases, the application process was considered "sloppy". As expected, magistrates expressed a great deal of frustration about the lack of specifically allocated resources to implement the Act in the way that the legislature intended. Overstretched courts and personnel, insufficient office supplies and office space, lack of telecommunications, meagre court budgets and other basic infrastructural needs compounded an already over-burdened system.

Heavy caseloads mean that clerks of the court are necessarily hasty in filling out forms and in instructing applicants about procedures, documentation that needs submitting to the courts, and safety measures to protect themselves from further violence. It was consistently argued that the files containing the application forms were "sketchy" at best and could be one reason for the apparently "conservative decisions" made by magistrates in domestic violence cases. Magistrates re-iterated that the dearth of information contained in the court papers was not necessarily due to a lack of effort or competence, but rather a lack of consultation time with applicants.

Despite the confidence expressed in the potential of the DVA and their relative effectiveness in implementing the Act, more sober reflections revealed that magistrates do not feel entirely confident that they are 'doing the right thing'.
Training on the social context of domestic violence and the specific elements of the Act was seen as an important step in improving judicial approaches to the DVA. Working groups and workshops were considered "essential" to the development of magistrates who preside over these cases. The opportunity to be presented with current research and case studies as well as hearing how other magistrates deal with the 'grey' issues of domestic violence was cited as critical to improving how magistrates implement the Act. After four years of working with the Domestic Violence Act, a magistrate had this to say about training:

What can I say about training? I was trained second-hand - by a colleague who went to Justice College to be trained specifically on the Act. After presiding over domestic violence cases for a few years, I have realised that the Act is open to wide interpretation and that I fundamentally disagree with my colleague's approach to this Act. I can confidently state that whatever training took place was given to the wrong people and that whoever did the training has never presided over a domestic violence case before or has done little to understand the ins-and-outs of the Act.

\section{Applications for a protection order}

Domestic violence caseloads vary considerably across magisterial jurisdictions with some magistrates reporting reviewing 40 applications a day, and others only about ten. This obviously has serious implications for how the cases are treated. One magistrate incisively explained the impact of the high number of applications on his court:

When you find yourself sitting with 30-40 applications a day, you begin to feel like your court has turned into an assembly line. The cases all begin to look the same and the time that you would like to spend...going through each application thoroughly... is terribly diminished. You begin to question the effectiveness of the system and the accuracy of your own judgment. You ask yourself whether you are granting this person this order because another person 
earlier that day was granted a similar order, but the facts are completely different, and so on. The scope of the Act is wide enough to provide tailor-made protection orders to suit the circumstances presented to you, but you find yourself providing the same relief to everyone...despite your better judgment. There is little time to carefully examine these applications and to grant orders that specifically suit the situation. There are far too few magistrates dealing with domestic violence to give the Act its full effect.

Concern was also expressed about the apparent urgency of some applications. With high caseloads, the courts are sometimes unable to grant interim orders on the day that the application is made. Although section 6 of the application form allows the applicant to motivate "why the court should consider the application as a matter of urgency" and "why undue hardship may be suffered by the applicant if the application is not dealt with immediately", this section seldom provides any more information than what is already contained in the affidavit.

Although the contents of section 6 have on occasion convincingly argued the case for an urgent application, the general consensus among magistrates was that there is rarely sufficient information in this section to warrant an urgent protection order. Applications are therefore processed on a 'first come, first serve' basis meaning that applications that cannot be reviewed on the same day are postponed to the following day(s).

In light of this, it was suggested that the courts, individually or collectively, develop a set of criteria for what constitutes "urgency" and "undue hardship". This would enable clerks of the court to prioritise cases that required urgent intervention and ensure that applicants are sufficiently protected. It was emphasised that these criteria do not have to be inclusive, but instead consist of a 'guiding' set of circumstances that would warrant urgency. As with other issues debated, precisely what constitutes "imminent harm", "undue hardship" and "urgency" remained controversial. The only real consensus among magistrates about what constitutes "urgency" and "imminent harm" in domestic violence cases includes situations in which:

- the respondent is in the possession of a firearm and has threatened to use the firearm against the applicant, or her dependents or other family members;

- the respondent has used a weapon against the applicant in previous incidences of domestic violence (not restricted to firearms or knives);

- the applicant was critically injured by the respondent on a previous occasion, or on the occasion in question;

- the applicant and her children have been 'kicked out' of the shared residence by the respondent or anyone affiliated with the respondent;

- the applicant has sufficient evidence (i.e. witness statements) that the respondent has threatened to harm her/him;

- the applicant fears for the safety of her children.

Clearly, these criteria do not sufficiently address the perceived risk of applicants of further and imminent harm. They also exclude a wide range of behaviours that may be threatening to the safety, health and wellbeing of the applicant and his/her dependents, such as stalking, harassment and economic abuse. The emphasis on physical abuse is worrisome and defeats the object of ensuring full protection against all forms of domestic violence set out in the definition of the Act.

\section{Reading the affidavit}

Great discrepancies were found between the various sections of the application for a protection order filled out by the complainant. ${ }^{3}$ The description of the abuses set out in the affidavit often did not correspond to the information completed in the rest of the form. An attempt was made to compare the affidavit with requests for cessation of abuses in section (7)(a) or (h) of Form 2 (Terms of the Protection Order in the application form), and the orders granted by the magistrate (Table 1 ).

The following discrepancies were found between the affidavits and the application orders:

- Although physical abuse was mentioned in 415 affidavits, orders against physical violence were requested in $54 \%$ of cases. 


\begin{tabular}{|c|c|c|c|c|c|c|c|c|c|}
\hline \multirow[t]{2}{*}{$\begin{array}{l}\text { Type of abuse } \\
\text { noted }\end{array}$} & \multicolumn{3}{|c|}{$\begin{array}{c}\text { Court A } \\
n=170\end{array}$} & \multicolumn{3}{|c|}{$\begin{array}{c}\text { Court B } \\
n=279\end{array}$} & \multicolumn{3}{|c|}{$\begin{array}{c}\text { Court C } \\
n=160\end{array}$} \\
\hline & Affidavit & $\begin{array}{l}\text { Request } \\
\text { for order }\end{array}$ & $\begin{array}{l}\text { Order } \\
\text { granted }\end{array}$ & Affidavit & $\begin{array}{l}\text { Request } \\
\text { for order }\end{array}$ & $\begin{array}{l}\text { Order } \\
\text { granted }\end{array}$ & Affidavit & $\begin{array}{l}\text { Request } \\
\text { for order }\end{array}$ & $\begin{array}{l}\text { Order } \\
\text { granted }\end{array}$ \\
\hline Physical & 111 & 47 & 151 & 184 & 159 & 236 & 120 & 18 & 146 \\
\hline Sexual & 20 & 2 & 0 & 19 & 3 & 7 & 7 & 3 & 0 \\
\hline $\begin{array}{l}\text { Emotional/ } \\
\text { verbal/ } \\
\text { psychological }\end{array}$ & 137 & 90 & 111 & 251 & 240 & 244 & 132 & 87 & 20 \\
\hline Economic & 45 & 10 & 15 & 92 & 3 & 18 & 35 & 7 & 2 \\
\hline Intimidation & 81 & 76 & 160 & 92 & 22 & 10 & 9 & 3 & 127 \\
\hline Harassment & 21 & 57 & 73 & 15 & 7 & 0 & 6 & 3 & 1 \\
\hline Stalking & 11 & 19 & 43 & 7 & 4 & 1 & 4 & 5 & 1 \\
\hline $\begin{array}{l}\text { Damage to } \\
\text { property }\end{array}$ & 45 & 22 & 24 & 42 & 4 & 24 & 33 & 12 & 11 \\
\hline $\begin{array}{l}\text { Entry without } \\
\text { consent }\end{array}$ & 9 & 11 & 4 & 9 & 1 & 3 & 13 & 1 & 1 \\
\hline Other & 63 & $*$ & 19 & 121 & $*$ & 5 & 10 & $*$ & 0 \\
\hline
\end{tabular}

- Only $17 \%$ of application forms mentioning sexual abuse requested protection from this.

- Only $11 \%$ of application forms mentioning economic abuse requested protection from this.

- $55 \%$ of application forms mentioning intimidation requested protection from this.

- Only $32 \%$ of application forms mentioning property damage requested protection from further damage.

It is evident that there is a great deal of variance between how victims experience abuse (as per the affidavit) and how the clerks of the court tend to 'systemise' or narrowly categorise the abuse. The results also illustrate how magistrates, in some instances, grant particular conditions to applicants for more comprehensive protection, despite what was applied for in the application form. This is particularly true for cases of physical abuse, harassment and stalking.

Magistrates reported that reading the affidavit against the application form was essential and constituted the basis for the decision to grant a protection order. It was also reported that any indication of physical violence and/or the threat of physical violence (often referred to as "intimidation") in the affidavit resulted in an unequivocal decision to grant the applicant protection from further physical violence. This was the case regardless of whether section 7 (a) or $7(h)^{4}$ of the application forms were specific about physical violence or not. 


\section{Beyond physical violence}

Less convincing for magistrates were applications involving sexual violence, economic abuse and psychological/emotional abuse. Magistrates presented numerous scenarios that revealed a strong scepticism - or perhaps cautiousness - about these three forms of domestic violence. The scenarios were wide-ranging and represented both the complexity of presiding over these matters as well as pervasive myths, preconceptions and deep biases about domestic violence and the 'intentions of women' in applying for protection orders.

Each case brings a new set of circumstances and a new set of facts and should be treated with the appropriate, individual attention. Of particular concern are the following notions about domestic violence that may impede appropriate justice for applicants seeking protection:

- Some women apply for protection orders because they are angry about their husband's or partner's infidelity. Protection orders should therefore not be issued when there is evidence of extra-marital relationships or when the couple has separated due to an extra-marital relationship.

- Women often apply for emergency monetary relief because they were unsuccessful in getting maintenance from their partners.

- Sexual violence is not common in marriage or long-term domestic relationships.

- Some women apply to have their husbands/ partners removed from the shared residence so that their new boyfriends can stay with them.

- Some women apply for protection orders against 'emotional abuse', but they are in no real danger of being harmed.

- Some women use the 'excuse' of being concerned about the safety of their children to get a protection order. However, it is really their partners they are trying to punish for something they did to them.

- Some applicants (both men and women) use the Domestic Violence Act to further their own cause in divorce or custody proceedings.

While it is true that relationships between people are complex, and that 'third parties' and financial matters create antagonism in domestic relationships, magistrates need to seriously consider the possibility that the breakdown or dissolution of the relationship may put the applicant at risk of harm.

While some applicants may abuse the DVA - as much as people abuse the services of the police, the ambulance service, the fire department, 10111 call centres and the courts, more generally - the default position that assumes that applicants are 'getting back' at their partners, are not 'abused enough', are equally abusive or are in 'no real danger' when physical abuse is not present, is a weak premise from which to make decisions. What appear to be minor domestic conflicts or abuses can easily escalate over a short period of time. Emotional abuse is quickly translated into serious physical and sexual violence and therefore should be considered as serious as physical violence when granting protection orders.

It was also found that court personnel become desensitised to matters of inter-personal violence, particularly non-physical abuses experienced by complainants. It was suggested that in order to circumvent "personal biases" by the magistracy, magistrates should base their decisions on intensive interrogation of the facts presented to the court. ${ }^{5}$ In order for the Act to work effectively, the decision to grant a protection order, or specific conditions thereof, must be based on the assumption that the applicant's reason for applying for an order are bona fide until proved otherwise.

\section{The impact of police work}

Magistrates were careful to point out that they are, to some extent, victims of the "domino effect": their decisions are dependant on how well the other agents of the criminal justice system manage an incident of domestic violence and document investigations. When police and witness statements are poor, missing or even illegible, the case against an accused/respondent is weakened.

While acknowledging that it is up to magistrates to discern the relevance of the papers presented to the court and to further interrogate the matter until a reasonable decision can be made, magistrates reported that the quality of these papers is often very unsatisfactory. The extent to which magistrates 
saw themselves as being effective was greatly dependent on the previous interventions and interactions with these 'frontline' workers.

The magistrates were, however, very sympathetic to the 'triage-type' working conditions and demands placed on clerks of the court. They argued that if the police took better statements from complainants, clerks could spend more time providing applicants with detailed information about the relevant criminal and civil procedures. It was recommended that when an incident of domestic violence is reported to the police, the statement taking should include these five essential questions:

- the history of the abuse;

- a description of the most recent incidence of domestic violence;

- any medical attention sought by the complainant as a result of the current incident or previous incidents or any other evidence to show that an act of domestic violence has taken place;

- the complainant's knowledge of any previous criminal records of the accused;

- the complainant's knowledge of any orders against the accused (protection orders, interdicts under the Prevention of Family Violence Act, 1993, maintenance orders, eviction orders, and so on).

It was suggested that these questions would assist the court in providing a more informed and comprehensive service to the applicant.

Acknowledging that transforming police responses to domestic violence cases was a long term prospect and that over-burdened clerks often find little time to fully explain the range of legal remedies to applicants, it was recommended by some that magistrates themselves play a greater role in advising both applicants and respondents at the Return Date. The idea that magistrates take on this 'additional clerk's duty' however, became a contentious issue. It was argued that:

By advising the applicant of her [or his] rights, the magistrate becomes a 'legal advisor' and therefore becomes impartial. The magistrate is in no position to be a legal advisor. There are other people to advise the applicant on her rights under the Act.

A magistrate cannot be impartial if he is acting as an investigating officer... and has given legal advice to the applicant... especially when the respondent has not been heard at this stage.

A more moderated position about the role of magistrates in explaining the remedies available under the Domestic Violence Act was:

It must be clear...that the magistrate is not giving legal advice. It must be stressed that the magistrate is simply re-iterating the legal options set out in the Act and reinforcing the information that the clerk of the court or the court volunteer has given to the applicant.

The final recommendation by magistrates was that magistrates should inform both the applicant and the respondent about the remedies available under the Act as well as other legal options such as applying for maintenance, custody, evictions or divorce, and still retain the role of impartial observer to the proceedings. Although it was pointed out that section 2 and 4 of the Act, as well as Regulation 3 and 5 of the Act, provide that the clerk of the court should undertake this role, it was largely agreed that informing the applicant and respondent of their rights, remedies and obligations under the Act, "could do no harm". It was argued that a magistrate could explain the legal options available under the Domestic Violence Act, or any other relevant Act to the applicant, without necessarily advising the applicant on which options she/he should take.

\section{Counter protection orders}

Counter protection orders - orders that are applied for by a respondent against a complainant - were cited as an increasing problem for magistrates. The current system of file management does not allow for accurate tracking of counter protection orders.

Respondents rarely voluntarily submit information of orders issued against them when applying for an order against someone else, and court clerks do not 
have the capacity to cross-reference applications for counter orders. However, magistrates and clerks do identify applications for counter protection orders, simply by remembering, by name or by sight, the original applicant or respondent. The magistrates estimated that between $5 \%-30 \%$ of applications are counter protection orders and that this was on the increase:

You see more and more of these things. One party gets an order then the other party gets another order to retaliate. It's not that uncommon, but the courts are quickly wising up to it. It is very difficult to track if you don't have good record-keeping systems at the court and the second applicant is very hesitant to say that the reason he is applying for a protection order is because his wife got one against him. My tolerance for these cases is limited. It wastes the courts time and it undermines the real purpose for the DVA. These people need to learn to play these games outside of my court.

Although counter protection orders may be necessary in some cases, the granting of such orders should be done with caution. In order to limit vexatious claims against the original applicant and to avoid granting conflicting orders between the two parties, it was recommended that:

- the court establishes whether the applicant is aware of any other orders against the respondent (including maintenance orders, protection orders);

- the court establishes whether the applicant has any orders against him/herself (including maintenance orders, protection orders);

- the court establishes whether any High Court orders are in place (such as custody orders);

- when existing orders are in place, the courts ensure that those orders are entered into the court file and that any new orders issued do not contradict the existing orders. It may, however, be the case that an urgent application is required to provide the new applicant with temporary relief from domestic violence. In this case, the court should consider providing such relief until the original order can be varied or amended.

\section{Conclusion}

Despite the impression that magistrates have a tendency to adjudicate domestic violence matters conservatively, both the empirical research from the First Report ${ }^{6}$ and this recent study with magistrates have illustrated that most magistrates take a 'better safe, than sorry' approach in granting particular conditions in protection orders. The general sentiment of magistrates is that it makes more sense to have an all-inclusive protection order, than one that will be subject to variation at a later stage. Still, decisions regarding emergency monetary relief, removal of the respondent from the shared residence and contact orders with children are reportedly treated with much more caution than the other remedies available under the Act.

Local court monitoring initiatives are therefore essential in ensuring that the DVA is implemented in a way that ensures both procedural consistency and legal uniformity. Local data on magisterial interpretation of the Act is essential to improve overall decision-making. To ensure that the DVA is implemented equitably, 45 magistrates have contributed to the development of guidelines for the implementation of the DVA. It is hoped that these guidelines will be Gazetted in the near future and assist magistrates in more effective decisionmaking. ${ }^{\text {? }}$

\section{Endnotes}

1 Parts of this article were originally published in L Artz, Magistrates and the Domestic Violence Act: Issues of Interpretation, Institute of Criminology, Faculty of Law, University of Cape Town, 2003.

2 This study was conducted to investigate the various approaches by magistrates in implementing the Act. Broadly, the study involved the re-examination of our monitoring database on the DVA (see P Parenzee, L Artz \& K Moult, Monitoring the Domestic Violence Act: First Report, Institute of Criminology, Faculty of Law, University of Cape Town, 2001); in-depth interviews with magistrates from each of the nine provinces; the analysis of the outcomes of two major conferences (including over 350 magistrates and High Court judges, facilitated by this author and her associates); as well as the outcomes of monthly meetings with the Domestic Violence Working Group (a group consisting of magistrates representing each province, the Justice Training College, the Gender Directorate of the Department of Justice and the author).

3 P Parenzee, et al, ibid. 
4 S. 7 contains the Terms of the Protection Order.

5 This may be done with the applicant and the respondent, on the Return Date. The regulations of the Act do provide, in a notice to the applicant, that if the applicant knowingly gives false information when applying for a protection order or when laying a criminal charge, the applicant may be prosecuted.

6 P Parenzee, et al, op cit.

7 See L Artz, op cit. 